\title{
HEP-Net opinion on the management of ascites and its complications in the setting of decompensated cirrhosis in the resource constrained environment of Pakistan
}

\author{
Bushra Ali ${ }^{1}$, Adnan Salim², Altaf Alam ${ }^{3}$, Bader Faiyaz Zuberi ${ }^{4}$, Zeeshan Ali \\ Zahid Azam ${ }^{6}$, Lubna Kamani ${ }^{7}$, Javed lqbal Farooqi ${ }^{8}$, Muhammed Salih', \\ Arif Amir Nawaz ${ }^{10}$, Asad Ali Chaudhry ${ }^{11}$, Zahid Yasin Hashmi' ${ }^{12}$, Masood Siddique ${ }^{13}$
}

\begin{abstract}
Approximately one half of patients develop ascites within 10 years of diagnosis of compensated cirrhosis. It is a poor prognostic indicator, with only $50 \%$ surviving beyond two years. Mortality worsens significantly to $20 \%$ to $50 \%$ at one year if the ascites becomes refractory to medical therapy. Pakistan has one of the highest prevalence of viral hepatitis in the world and patients with ascites secondary to liver cirrhosis make a major percentage of both inpatient and outpatient burden. Studies indicate that over $80 \%$ of patients admitted with ascites have liver cirrhosis as the cause.

This expert opinion suggests proper assessment of patients with ascites in the presence of underlying cirrhosis. This expert opinion includes appropriate diagnosis and management of uncomplicated ascites, refractory ascites and complicated ascites (including spontaneous bacterial peritonitis (SBP) ascites, hepatorenal syndrome (HRS) and hyponatremia. The purpose behind this expert opinion is to help consultants, postgraduate trainees, medical officers and primary care physicians optimally manage their patients with cirrhosis and ascites in a resource constrained setting as is often encountered in a developing country like Pakistan.
\end{abstract}

KEYWORDS: Cirrhosis; Ascites; Portal Hypertension; Spontaneous bacterial peritonitis; Hepatorenal syndrome; Refractory ascites.

How to cite this:

doi: https://doi.org/10.12669/pjms.36.5.2407

Ali B, Salim A, Alam A, Zuberi BF, Ali Z, Azam Z, et al. HEP-Net opinion on the management of ascites and its complications in the setting of decompensated cirrhosis in the resource constrained environment of Pakistan. Pak J Med Sci. 2020;36(5):1117-1132. doi: https://doi.org/10.12669/pjms.36.5.2407

This is an Open Access article distributed under the terms of the Creative Commons Attribution License (http://creativecommons.org/licenses/by/3.0), which permits unrestricted use, distribution, and reproduction in any medium, provided the original work is properly cited.

\section{Burden of Disease:}

Approximately one half of patients develop ascites within 10 years of diagnosis of compensated cirrhosis. ${ }^{1}$ It harbingers a new phase of cirrhosis called decompensated cirrhosis resulting in significant deterioration of prognosis. It is a poor prognostic indicator, with only 50\% surviving beyond two years. ${ }^{2,3}$ Mortality worsens significantly

Correspondence:

Prof. Bader Faiyaz Zuberi,

Dow Medical College, Dow University of Health Sciences,

Karachi, Pakistan.

Email: bader@zuberi.net

* Received for Publication:

February 23, 2020

* $1^{\text {st }}$ Revision Received:

* $\quad 2^{\text {nd }}$ Revision Received:

* Final Revision Accepted: to $20 \%$ to $50 \%$ at one year if the ascites becomes refractory to medical therapy. ${ }^{4}$ Pakistan has one of the highest prevalence of viral hepatitis in the world and patients with ascites secondary to liver cirrhosis make a major percentage of both inpatient and outpatient burden. Studies indicate that over $80 \%$ of patients admitted with ascites have liver cirrhosis as the cause..$^{5-8}$ Most common cause of cirrhosis in Pakistan is reported as hepatitis C infection in over half of the such patients. ${ }^{9}$

Diagnosis of Ascites:

The initial evaluation of ascites includes detailed history, physical examination, abdominal ultrasound, liver function tests including serum albumin and INR, renal function tests, serum electrolytes and spot urinary electrolytes. Ascitic fluid should be analyzed to calculate serum 


\section{GRADING SYSTEM USED IN RECOMMENDATIONS}

\begin{tabular}{|c|c|c|}
\hline \multicolumn{2}{|l|}{ DESCRIPTION } & $S Y M B O L$ \\
\hline \multicolumn{3}{|l|}{ GRADING OF EVIDENCE } \\
\hline High & $\begin{array}{l}\text { Further research is very unlikely to change our confidence in the estimate of } \\
\text { effect }\end{array}$ & A \\
\hline Moderate & $\begin{array}{l}\text { Further research is likely to have an important impact on our confidence in } \\
\text { the estimate } \\
\text { of effect and may change the estimate }\end{array}$ & B \\
\hline Low or very low & $\begin{array}{l}\text { Further research is very likely to have an important impact on our } \\
\text { confidence in the estimate of effect and is likely to change the estimate. Any } \\
\text { estimate of effect is uncertain }\end{array}$ & $\mathrm{C}$ \\
\hline \multicolumn{3}{|c|}{ GRADING RECOMMENDATION } \\
\hline Strong recommendation & $\begin{array}{l}\text { Factors influencing the strength of the recommendation included the quality } \\
\text { of evidence, } \\
\text { presumed patient-important outcomes, and cost }\end{array}$ & I \\
\hline $\begin{array}{l}\text { Weaker } \\
\text { recommendation }\end{array}$ & $\begin{array}{l}\text { Variability in preferences and values, or more uncertainty: more likely a } \\
\text { weak recommendation is warranted } \\
\text { Recommendation is made with less certainty: higher cost or resource } \\
\text { consumption }\end{array}$ & II \\
\hline
\end{tabular}

albumin to ascitic fluid albumin gradient (SAAG). ${ }^{10}$ A SAAG of more than or equal to 1.1 is defined as high SAAG ascites while it is low SAAG if this ratio is less than 1.1. The following document elaborates upon management of high SAAG ascites only.

DEFINITIONS:

Uncomplicated ascites: Uncomplicated ascites is defined as ascites that is not infected and is not associated with refractoriness to conventional medical treatment, development of hyponatremia, spontaneous bacterial peritonitis, or hepatorenal syndrome. ${ }^{10}$

Complicated ascites: Complicated ascites is defined as ascites with complications of one or more of the following: Spontaneous bacterial peritonitis (SBP) hepatorenal syndrome (HRS) and hyponatremia. ${ }^{10}$

Refractory ascites: Ascites that cannot be mobilized with maximum dose of diuretics (furosemide 160 $\mathrm{mg} /$ day and spironolactone $400 \mathrm{mg} /$ day) or the early recurrence (within 2 weeks) of which [i.e., after Large volume paracentesis (LVP) of 5 liters or more of ascitic fluid] cannot be satisfactorily prevented by medical therapy. ${ }^{11,12}$

Management of Uncomplicated Ascites: Ascites may be classified into three grades depending upon the quantity of free fluid in the peritoneal cavity.
Choice of treatment depends upon this clinical quantification of fluid: ${ }^{13,14}$

It is essential to carry out biochemical, microscopic and microbiologic analysis of ascitic fluid. Biochemistry includes total protein, albumin, LDH and glucose content of ascitic fluid. The total leucocyte count and differential leucocyte count (TLC and DLC) must be checked. Ascitic fluid ought to be sent in blood culture bottles for culture/ sensitivity. Reagent strips for leucocyte esterase have been successfully used for bedside diagnosis of SBP in some studies. ${ }^{15}$

It is important to rule out spontaneous bacterial peritonitis (SBP) if ascites in new in onset or worsening of ascites is noted. SBP should also be ruled out in those who get hospitalized with any complication of cirrhosis or for any other medical or surgical reason. ${ }^{16,17}$ The total protein content will also help assess the future risk of SBP. Ascitic fluid analysis should still be carried out at every admission regardless of the time period between current admission and previous discharge to rule out SBP.

\section{Recommendations:}

- All patients with ascites must undergo a complete history, examination and relevant

Grades of ascites Definition

\begin{tabular}{lll}
\hline Grade 1 & Mild ascites only detectable on ultrasound & No treatment \\
Grade 2 & Moderate ascites with moderate symmetrical distension of abdomen & Salt restriction and diuretics \\
Grade 3 & $\begin{array}{l}\text { Large or gross ascites with marked abdominal distension/ } \\
\text { tense ascites }\end{array}$ & $\begin{array}{l}\text { Therapeutic paracentesis } \\
\text { followed by salt restriction and diuretics }\end{array}$ \\
\hline
\end{tabular}


investigations along with ascitic fluid analysis to calculate SAAG and to rule out spontaneous bacterial peritonitis

- Ascitic fluid analysis is essential in cases of cirrhosis with new onset ascites, worsening ascites, or those admitted with other complications of cirrhosis.

Management of moderate ascites: Treatment of moderate ascites is aimed at counteracting the increased renal reabsorption of sodium by restricting salt intake and increasing sodium excretion with diuretics.

\section{DIURETICS AND SALT RESTRICTION:}

A diet with sodium content of less than $2 \mathrm{~g}$ or $88 \mathrm{mmol}$ per day (equivalent to $5 \mathrm{~g}$ of table salt per day) must be stressed upon. This is roughly equal to one heaped teaspoon or two flat teaspoons of table salt. Diuretic dose can be increased stepwise every week, while maintaining a ratio of $40 \mathrm{mg}$ of furosemide for every $100 \mathrm{mg}$ of spironolactone. A maximum daily weight loss of $0.5 \mathrm{~kg} /$ day is reasonable in the absence of pedal edema. There is no restriction to weight loss if massive pedal edema accompanies ascites. ${ }^{1,4}$ Mild to moderate ascites should be managed by modest salt restriction and diuretic therapy with spironolactone or an equivalent in the first instance. Diuretics should be added in a stepwise fashion while maintaining sodium restriction. Gross ascites should be treated with therapeutic paracentesis followed by colloid volume expansion, and diuretic therapy. Refractory ascites is managed by repeated large volume paracentesis or insertion of a transjugular intrahepatic portosystemic stent shunt (TIPS). ${ }^{18}$

Diuretics may require dose adjustment in summer months due to increased fluid losses. Diligent follow up of patients, every 1-2 weeks to begin with, is required as the dose of diuretics is stepped up for weight loss documentation, orthostatic hypotension, electrolyte imbalance, pre-renal azotemia, and signs of portosystemic encephalopathy as a result of diuretic overdose. ${ }^{19}$

All patients with ascites should not be advised to restrict their fluid intake. Restriction of fluid intake should only be advised in the small minority who have documented serum sodium of below $125 \mathrm{mmol} / \mathrm{L}^{14,20}$ Intravenous furosemide is best avoided since it causes rapid fluid shifts and an acute reduction in renal perfusion leading to azotemia. This azotemia may be mistaken for hepatorenal syndrome when in fact it is diuretic induced and is corrected once diuretics are withheld and dehydration is corrected. ${ }^{19}$
Spot urinary sodium to potassium ratio is a convenient alternative to 24-hour urinary sodium while assessing outpatient response to diuretic therapy. When this ratio is more than one, it suggests adequate diuresis. ${ }^{19}$ Adequate diuresis is also suggested by a urinary sodium excretion of more than $30 \mathrm{mmol} /$ day. ${ }^{19}$ Regular albumin infusions as per need or every two weeks have been recommended in some studies as an adjunct to diuretics and improved survival has been claimed. ${ }^{4,10,12}$ It is recommended that diuretics be taken in once daily dose in morning for better compliance and response. ${ }^{21}$

Recommendations:

- Patients should be advised not to take more than 5 grams of table salt or $88 \mathrm{mmol} / 2 \mathrm{~g}$ of sodium daily. (I-A)

- Diuretics should be given in a once daily dose (I-A)

- Diuretics should be introduced in a step-up dose at a ratio of 100:40 of spironolactone: furosemide(I-A)

- Weight, blood pressure, serum electrolytes, creatinine must be checked at every OPD visit along with examination for orthostatic hypotension and signs of portosystemic encephalopathy. (I-A)

- The frequency of outpatient visit should be once every one to four weeks depending upon the response to treatment(I-A)

- Spot urinary sodium to potassium ratio can be checked to assess response to diuresis. (II-A)

- Patients should be advised to stop diuretics if urinary sodium is $<30 \mathrm{mmol} /$ day. (II-A)

- Diuretics should also be stopped if serum sodium is < $120 \mathrm{mmol} / \mathrm{L}(1-\mathrm{B})$

- Regular use of intravenous furosemide should be best avoided. (I-B)

- Fluid restriction to $1000 \mathrm{ml}$ /day is effective in increasing serum sodium concentration in only a minority of patients with hypervolemic hyponatremia, but may be effective in preventing a further reduction in serum sodium levels (1-A).

Effects of Other Drugs Commonly Used By The Cirrhotic Patient:

- Studies have shown that beta-blockers may increase mortality in patients with refractory ascites by causing hemodynamic instability. ${ }^{22}$ Hence they should be used with caution (II-A).

- Angiotensin converting enzyme inhibitors and angiotensin receptor blockers are best avoided in patients with cirrhosis and ascites. ${ }^{23,24}$ (II-B). 
- It is best not to prescribe aminoglycosides, NSAIDs and other nephrotoxic drugs in patients with cirrhosis and ascites and should be used when other antibiotic or analgesics options are not available and under careful monitoring of renal function (II-A). ${ }^{25-27}$

\section{Management of large volume or tense ascites} Treatment Options available are:

- Paracentesis

- Diuretics

- Liver Transplant

Paracentesis: Paracentesis is a procedure in which a needle or catheter is introduced into the peritoneal cavity to obtain ascitic fluid. It is either done to establish etiology of new-onset ascites or to rule out spontaneous bacterial peritonitis. It is also carried out for therapeutic purpose. ${ }^{28-30}$

Ideal Method of Paracentesis: The left lower quadrant is the best site for a paracentesis. The anterior abdominal wall is thinner $3 \mathrm{~cm}$ above and $3 \mathrm{~cm}$ medial to the left anterior superior iliac spine. Most of the fluid gravitates at this site in comparison to the midline. This location also best avoids a distended cecum due to lactulose that is commonly used in patients with cirrhosis and the inferior epigastric arteries running in the rectus sheath. A 1.0 or 1.5 inch 20 or 22-gauge needle can be used for paracentesis. Patients with obesity may require a 3.5 inch needle. In those patients where fluid is difficult to localize, ultrasonography can be used for guidance. Paracentesis is best performed by a doctor who is trained for the procedure ${ }^{31}$ Recently introduced co-axial insertion technique is better than the routine z-technique of inserting cannula for Large Volume Paracentesis (LVP). ${ }^{32}$ LVP is removal of an amount greater than $5 \mathrm{~L}$ of ascitic fluid and is performed when tense ascites leads to discomfort and respiratory embarrassment or in cases with refractory ascites. ${ }^{31}$ Thrombocytopenia and coagulopathy do not preclude paracentesis FFP transfusion is not needed for correction of deranged INR prior to paracentesis for countering deranged INR. ${ }^{33}$

\section{Colloid Replacement:}

LVP ought to be followed by intravenous human albumin infusion to decrease the chances of PPCD. To prevent PPCD, $8 \mathrm{~g}$ of $20 \%$ human albumin is transfused for each liter of ascitic fluid removed when a LVP is performed. ${ }^{34,35}$ Half dose albumin, ${ }^{36}$ polygeline, ${ }^{37}$ dextran- $70^{38}$ and normal saline ${ }^{39}$ have been used as alternatives to albumin but without convincing results to show that they hold the same efficacy as albumin ( $8 \mathrm{gm} / \mathrm{L}$ of fluid removed) and are thus not recommended. If less than $5 \mathrm{~L}$ of ascitic fluid is planned to be removed, albumin infusion can be foregone. Large volume/tense ascites is best managed by LVP followed by diuretic use and a salt restricted diet.

Safety of LVP: Paracentesis of over 5 litres has been shown to be safe in critically ill patients with tense ascites. It improves respiratory function in such patients including those who are mechanically ventilated with minimal circulatory compromise. ${ }^{35,40}$ Large volume paracentesis is better avoided in patients with spontaneous bacterial peritonitis. Some portion of fluid may be removed to bring about relief in symptoms of discomfort or respiratory distress. A few studies have shown that paracentesis under cover of intravenous albumin is feasible in patients with spontaneous bacterial peritonitis and tense ascites without any increase in mortality. ${ }^{17,41,42}$

Paracentesis is safe in patients with hepatorenal syndrome and tense ascites. In fact, increased intraabdominal pressure may add to renal compromise. Paracentesis can be performed in such cases with albumin infusion and results in improvement in renal function. ${ }^{35}$ The standard LVP technique consists of placing an $16 \mathrm{G}$ catheter over needle (Intravenous branula) into the peritoneal cavity under aseptic measures, under local anesthesia and draining the fluid into either bags or vacuum containers. The other option is an indwelling peritoneal catheter which can be used to perform paracentesis over several days, as demonstrated in certain trials. Increased risk of bacterial infection of ascitic fluid was noted if the catheter was left for 3 or more days. ${ }^{43,44}$

Albumin is known to reduce PPCD but its use after an LVP has not shown any difference in clinical outcomes including encephalopathy, hyponatremia, readmission, renal impairment and death. However in cirrhotic patients with any infection, albumin use may significantly reduce sepsis related mortality and renal impairment. . $^{30,45,46}$

\section{Recommendations:}

- Thrombocytopenia and coagulopathy are not contraindications to paracentesis. Platelets or fresh frozen plasma need not be used to correct derangements. (I-A)

- Large volume paracentesis followed by diuretics is appropriate treatment in patients with diuretic sensitive tense ascites (I-A)

- Up to 5 litres of fluid can be removed without colloid support (I-A).

- Large volume paracentesis should be carried 
out under cover of $8 \mathrm{~g}$ of albumin for each litre of ascitic fluid tapped. (I-A).

- Patients must have their discharge weight documented and should be called for first follow up preferably after a week. (I-A)

- Patients must not be subjected to regular paracentesis if adequate weight reduction is achieved with diuretics and salt intake restriction after initial paracentesis. (I-A)

- Fresh frozen plasma (FFP) should not be used as an alternative form of colloid instead of albumin for paracentesis (I-A)

- Paracentesis (with intravenous albumin as colloid support) can be safely instituted in patients with tense ascites and spontaneous bacterial peritonitis (I-A)

- Paracentesis may be safely done in critically ill patients including those on mechanically assisted ventilation (I-B)

- Paracentesis with albumin infusion is safe in patients with hepatorenal syndrome and tense ascites (I-B)

- An indwelling peritoneal catheter can be used to perform paracentesis for up to 3 days (II-C)

\section{REFRACTORY ASCITES}

Definition and Diagnostic Criteria of Refractory Ascites: Ascites that cannot be mobilized or the early recurrence of which (i.e., after LVP) cannot be satisfactorily prevented by medical therapy.,47

Refractory ascites has two subtypes:

Diuretic-resistant ascites: Ascites that cannot be mobilized or the early recurrence of which cannot be prevented because of a lack of response to sodium restriction and permissible dose of diuretics Diuretic-intractable ascites: Ascites that cannot be mobilized or the early recurrence of which cannot be prevented because of the development of diuretic induced complications that preclude the use of an effective diuretic dosage

Requisites for a diagnosis of refractory ascites: ${ }^{10,14}$

1. Treatment duration: Patients must be on maximum permissible dose of diuretics i.e. upto spironolactone $400 \mathrm{mg}$ / day and furosemide 160 $\mathrm{mg} /$ day for at least 1 week. The patient must adhere to less than $88 \mathrm{mmol} /$ day of sodium in the diet.

2. Lack of response: Mean weight loss of less than $0.8 \mathrm{~kg}$ over 4 days and urinary sodium output less than the sodium intake. ${ }^{10}$

3. Early ascites recurrence: Reappearance of grade 2 or 3 ascites within 4 weeks of initial mobilization. ${ }^{14}$

4. Diuretic-induced complications:

- Diuretic-induced hepatic encephalopathy is the development of encephalopathy in the absence of any other precipitating factor

- Diuretic-induced renal impairment is an increase of serum creatinine by $>100 \%$ to a value $>2 \mathrm{mg} / \mathrm{dl}(177 \mathrm{mmol} / \mathrm{L})$ in patients with ascites responding to treatment

- Diuretic-induced hyponatremia is defined as a decrease of serum sodium by $>10 \mathrm{mmol} / \mathrm{L}$ from baseline to a serum sodium of $<125 \mathrm{mmol} / \mathrm{L}$

- Diuretic-induced hypo- or hyperkalemia is defined as a change in serum potassium to $<3$ $\mathrm{mmol} / \mathrm{L}$ or $>6 \mathrm{mmol} / \mathrm{L}$ despite appropriate measures

Clinical Implications of Refractory Ascites: ${ }^{4}$

- Dilutional hyponatremia

- Hepatorenal syndrome

- Spontaneous bacterial peritonitis

- Hepatic hydrothorax

- Spontaneous bacterial empyema

- Umbilical hernia

Treatment Options for Refractory Ascites:

- Large volume paracentesis

- TIPS

- Peritoneovenous shunt

- Liver transplantation

- Vaptans

- Automated Low Flow Ascites (ALFA) Pump

Large Volume Paracentesis and salt restriction:

Serial therapeutic paracenteses are helpful in control of ascites. ${ }^{12}$ If spot urine sodium to potassium ratio is less than one, it suggests a poor response to diuretics. Even in patients with no urine sodium excretion, paracenteses performed fortnightly usually controls ascites. $^{38}$ Diuretics should be stopped if urinary sodium excretion is less than $30 \mathrm{mmol} /$ day. $^{7}$

Patients requiring paracenteses of approximately $10 \mathrm{~L}$ or more, less than two weeks interval, are likely not following a salt restricted diet. ${ }^{47}$ Repeated therapeutic paracentesis should be reserved for those $10 \%$ patients who are proven to be diuretic refractory. Midodrine is as effective as albumin in reducing morbidity and mortality among patients with refractory ascites undergoing LVP at a significantly lower cost. Long-duration midodrine intake can be more useful than shorter duration intake in terms of improvement of renal perfusion and sodium excretion. ${ }^{48-51}$ Beta blockers have been proven to have a deleterious effect on survival in patients with refractory ascites and should be stopped. ${ }^{52,53}$

\section{Recommendations:}

- Serial paracenteses can safely be carried out on outpatient basis for patients with proven refractory ascites every two weeks (I-A) 
- Diuretics should be stopped if urinary sodium is less than $30 \mathrm{mmol} /$ day (II-A)

- A salt restricted diet of less than $2 \mathrm{~g}$ of sodium equivalent to $88 \mathrm{mmol}$ per day must be adhered to even in patients with refractory ascites (I-A)

- Recommendations for colloid replacement and safety of paracentesis remain the same as mentioned for management of tense ascites. (IIA)

- Beta blockers ought to be discontinued in patients with refractory ascites. (II-A)

Transjugular IntraHepatic Portosystemic Shunt (TIPS):

TIPS is a side-to-side portocaval shunt placed between the portal vein that has high pressure owing to portal hypertension, and hepatic vein with low pressure, to decompress the portal system. It is used in patients with refractory ascites and for patients with variceal hemorrhage that is poorly controlled by endoscopic methods. ${ }^{54-56}$

Earlier studies done with nonpolytetrafluoroethylene (PTFE) covered stents showed conflicting data as regards patient survival post TIPS. TIPS did show a better control of ascites and better prevention of hepatorenal syndrome. However, encephalopathy was higher in patients undergoing TIPS compared to those undergoing serial paracentesis. ${ }^{54-56}$ Newer data suggest a definite advantage in terms of liver transplant free (LTF) survival in patients undergoing TIPS as compared to those undergoing serial paracentesis, with the cost of higher rates of encephalopathy in the TIPS group. ${ }^{11}$

PTFE covered stents work better than uncovered stents in terms of failure rates. ${ }^{54}$ There is some local evidence to suggest that TIPS is a feasible option in patients not suitable for or as a bridge to transplantation in centres where expertise is available..$^{57}$

To undergo TIPS, the patient should not have cardiopulmonary disease and must have normal cardiac ejection fraction $(\sim 60 \%)$. Patients due to undergo TIPS must have a MELD score of 18 or below. ${ }^{54,56}$ Patients with MELD scores between 18 and 24 can undergo TIPS as a bridge to transplant. ${ }^{58-60}$ Hence carefully selected patients can undergo TIPS with the risk of higher incidence of post-TIPS heart failure, post TIPS portosystemic encephalopathy without any benefit in overall survival. ${ }^{58,61}$

\section{Recommendations:}

- TIPS is a feasible option in patients not suitable for or as a bridge to transplantation in centres where expertise is available (I-A).

- It is recommended that patients be evaluated for MELD score and cardiac ejection fraction before undergoing TIPS. (I-B)

- Elective TIPS cannot be encouraged in patients with severe liver failure, concomitant infection, worsening renal failure or cardiopulmonary disease (II-B)

- Only PTFE coated stents are preferred over uncovered stents due to lower shunt failure rates (I-A)

- Regular outpatient paracentesis is a feasible option in patients not suitable for TIPS or liver transplant (I-A)

- Diuretics must not be withheld following TIPS as TIPS may in fact convert diuretic refractory ascites to diuretic sensitive ascites (I-A)

\section{Peritoneovenous Shunt:}

A peritoneo-venous shunt is a shunt that drains peritoneal fluid from the peritoneum into either the internal jugular vein or the superior vena cava. ${ }^{51}$

The LeVeen shunt was surgically placed and is not commercially available anymore. ${ }^{51}$

The Denver shunt is a modified from of LeVeen shunt used for management of hydrocephalus. It is placed in a subcutaneous tunnel between the peritoneal cavity and the internal jugular vein by interventional radiologists under local anesthesia. ${ }^{51}$ Potential complications of the peritoneovenous shunt are shunt occlusion, infection, disseminated intravascular coagulation (DIC) manifesting as post-shunt coagulopathy, deep vein thrombosis, catheter breakage, and leaks. ${ }^{51}$

\section{Recommendations:}

- Peritoneovenous shunt placement is recommended for patients not suitable for regular outpatient paracentesis, TIPS or liver transplantation, in centres where expertise for performing such procedures is available. (I-A)

- Peritoneovenous shunt placement is not required in diuretic refractory patients who can come for regular outpatient paracentesis. (II-B)

\section{Liver Transplantation:}

Liver transplantation is a procedure in which the patient's diseased liver is replaced by a whole healthy liver (Deceased donor) or part of a healthy liver of a willing donor (Living donor).

The presence of refractory complicated ascites is one of the indications for liver transplantation in patients with decompensated cirrhosis. ${ }^{38}$

\section{Recommendation:}

- Since survival after refractory ascites develops is measured in months, such patients should be advised liver transplantation (I-A)

Vasopressin Receptor Antagonists (Vaptans): Arginine vasopressin (AVP) has a crucial role 
in regulation of water and sodium in the body. It acts via three receptor subtypes V1a, V1b, and V2 distributed throughout the body. Vaptans are nonpeptide vasopressin receptor antagonists (VRA). Tolvaptan and Conivaptan are examples. ${ }^{62}$

Due to the ability to cause loss of excess water, the Vaptans have a role in correction of hyponatremia and fluid overload in patients with heart failure and cirrhosis. Some studies recommend the agent Tolvaptan (FDA approved but it is not locally available). ${ }^{62-65}$

There are concerns regarding the safety of such agents as regards side effects such as worsening of portal hypertension leading to variceal hemorrhage, hypernatremia, dehydration, deranged renal function, and central pontine demyelination. ${ }^{66,67}$

\section{Recommendations:}

- Vaptans are newer agents but have potential side effects. The agent Tolvaptan may be used in cirrhotic patients with ascites and hyponatremia but patients need to be carefully monitored for side effects (III-C)

- There is no local evidence on use of vaptans in refractory ascites

\section{Automated Low Flow Ascites (ALFA) Pump:}

A surgically implanted pump that automatically transfers peritoneal fluid to the bladder has been undergoing trials for some time (Developed by Sequana Medical AG http://www.alfapump.com/ alfapump).

Limited data suggests that it is safe. However long term studies with larger patient populations are ongoing which will further establish main concerns about such a system, especially pump dysfunction (pump failure and bladder and peritoneal catheter related problems), infection, ascitic fluid leakage through wounds, bladder perforation and renal impairment. ${ }^{68-73}$

\section{Recommendations:}

- Insertion of ALFA pump should only be performed in specialist centres where expertise to place the pump and to deal with its potential complications is available. Pump placement should currently be ideally performed in the setting of a controlled clinical trial (II-C)

- No local evidence is available on results of ALFA pump

\section{Suggestions for Future Research:}

- To compare 4 grams of albumin versus 8 grams of albumin per litre of fluid removed during large volume paracentesis (LVP) in prevention of post paracentesis circulatory dysfunction.

- To study the number of patients with cirrhosis and ascites who go on to develop refractory ascites.

- To compare Terlipressin with Albumin versus albumin alone during paracentesis to prevent post paracentesis circulatory dysfunction.

- To diagnose diuretic resistant ascites by the 80 mg IV furosemide challenge test.

- To ascertain benefit of combination of IV albumin and IV furosemide in hypo-albuminemic patients.

- To study the likelihood of spontaneous bacterial peritonitis in patients undergoing large volume paracentesis with use of indwelling catheter.

- To study the efficacy of regular albumin infusions as an adjunct to diuretics for improved survival.

- To study timing and benefits of discontinuation of diuretics in patients with clinically undetectable ascites.

- To study efficacy of eplenerone in patients with cirrhosis and refractory ascites.

- To study the effect of peritoneovenous shunts by interventional radiologists in the local scenario.

\section{Spontaneous Bacterial Peritonitis:}

Situation in Pakistan:

The incidence of SBP in cirrhotic patients in Pakistan averages $27-38 \%$ of all patients admitted to hospitals, as noted in various studies. ${ }^{74-78} \mathrm{Up}$ to $10 \%$ of asymptomatic patients with cirrhosis presenting for routine outpatient checkups have been found to have SBP. ${ }^{77}$ It was also noted that female gender, history of portosystemic encephalopathy, bilirubin $>1 \mathrm{mg} / \mathrm{dL}$ and presence of UTI were noted as statistically significant factors among those with recurrent SBP. ${ }^{79}$ A MELD score of $\geq 16$ corresponds to higher incidence of SBP..$^{80,81}$ One study also noted a $34 \%$ recurrence rate of SBP in patients who had already experienced an episode of SBP. ${ }^{76,82,83}$ Zaman A et al \& Rajput MR et al observed that low ascitic fluid protein level correlates with development of SBP with high incidence noted in patients with levels lower than $1 \mathrm{~g} / \mathrm{dL}$ while recent studies state otherwise. ${ }^{84-88}$ Causative organisms were seen in the following frequency, E coli $66 \%$, S. pneumoniae $16 \%$, S aureus $8 \%$ and Klebsiella 8\%. ${ }^{74,77,89}$ Among rapid diagnostic tools for bedside diagnosis of SBP, the leukocyte esterase dipstick was found to have over $90 \%$ sensitivity, specificity, PPV and NPV to diagnose SBP..$^{90}$

One and two-year survival rates following an episode of SBP are $30-40 \%$ and $20-30 \%$, respectively. ${ }^{77}$ Once a patient develops SBP, mortality rates of around $30 \%$ are reported..$^{91}$ 


\section{Recommendations:}

- Ascitic fluid should be sent for total and differential leukocyte counts, Gram stain and cultures with antibiotic sensitivity in all patients with cirrhosis who are admitted to hospital for any reason, regardless of the interval between current and last admission. This should be done even if recent admission's ascitic fluid reports have ruled out SBP. This should be done prior to the administration of any antibiotics. Ascitic fluid samples must be transferred to culture bottles at the bedside and transferred for analysis to the laboratory within 30 minutes (IA)

- Administration of antibiotics to cirrhotic patients immediately following admission should be discouraged and these should only be started once a sample has been obtained for leucocyte counts. (I-A)

- All patients with cirrhosis and ascites presenting with signs of infection such as fever, abdominal pain or encephalopathy should receive empirical antibiotic treatment for possible SBP after ascitic fluid sampling. (I-A)

- Cefotaxime intravenously at a dose of $2 \mathrm{~g} 8$ hourly remains the first line antibiotic for all cases of confirmed or suspected SBP.(I-A)

- Ceftriaxone I.V at a dose of $1 \mathrm{~g} 12$ hourly is an alternative to the above regime. It is cost effective and has been shown to effectively control SBP. (I-A)

- Switching to a different antibiotic may be done if the patient does not clinically improve and shows a non-significant reduction in leukocyte counts on a repeat ascitic fluid sample obtained 48 hours after the first sample. (I-B)

- Modification to antibiotic regime must preferably be done in light of culture and sensitivity reports. (I-B)

- All patients should receive $1.5 \mathrm{~g}$ albumin per $\mathrm{kg}$ body weight within 6 hours of diagnostic paracentesis and $1.0 \mathrm{~g} / \mathrm{kg}$ on day 3. I.V albumin remains very expensive and lower doses of albumin need to be considered in light of new trials. (II-B)

- Proton pump inhibitors are massively overprescribed (one study quoting a figure of almost $70 \%$ patients having no clear indication for PPI use) and they may contribute to the development of SBP in patients with cirrhosis and ascites. PPIs must be used only in patients with clear documented dyspepsia and/or reflux and their use must be short duration as and when symptoms develop. (I-B)

- Secondary bacterial peritonitis must be ruled out in patients with very high leucocyte counts. (I-B)

- In such cases, ascitic fluid must be analysed for protein, glucose, LDH, Gram Stain and CEA along with a contrast enhanced CT of the abdomen \& pelvis area to rule-out/rule-in a focal source of infection. (I-B)

- Prophylaxis against SBP must be done in all cases of GI bleeding in patients with liver cirrhosis. (I-A)

- Prophylaxis against SBP in cases of GI bleeding in cirrhotic patients can be effectively done starting with $1 \mathrm{~g}$ daily of ceftriaxone and switching to oral therapy after endoscopy. (I-B)

- Oral therapy in aforementioned scenario is continued to day 7. (I-B)

- Oral agents that can be used include ciprofloxacin 500mg BID, levofloxacin 500mg OD or norfloxacin $400 \mathrm{mg}$ twice daily. (I-A)

- Prophylaxis against SBP is also required for the following two groups:

- Patients who have had one episode of SBP: Such patients require prophylaxis till death or liver transplantation. (I-A)

- Patients with ascitic fluid protein $\leq 1.5 \mathrm{~g} / \mathrm{dL}$ along with renal dysfucntion (creatinine $\geq 1.2$, BUN $\geq 25$ or serum $\mathrm{Na} \leq 130$ ) or advanced cirrhosis (Child score 9 and bilirubin 3). Such patients should preferably receive prophylaxis for one year. (I-A)

- Prophylaxis against SBP can be done using once daily doses of ciprofloxacin. It is advisable to use different antibiotics for treatment and prophylaxis in the same patient (II-A)

- Intermittent dosing (such as once weekly) of antibiotics for prophylaxis is not recommended as it may result in emergence of resistant strains of bacteria. (II-C)

\section{Suggestions for future research:}

- To study 6-month mortality in patients with and without regular antibiotic prophylaxis against SBP.

- To study the efficacy of ofloxacin and Trimethoprim-Sulfamethoxazole in prophylaxis against SBP.

- To study the difference in yield of TLC/DLC in ascitic fluid collected in vial with EDTA as against a plain syringe in SBP.

- To study the decrease in TLC in ascitic fluid after first dose of antibiotic in patients diagnosed with SBP. 
Baseline sCr

Definition of AKI

Staging of AKI
A value of sCr obtained in the previous 3 months when available can be used as baseline sCr. In patients with more than one value, the value closest to the time of admission must be used

- Increase in $\mathrm{sCr} \geq 0.3 \mathrm{mg} / \mathrm{dl}$ over 48 hours or

- A percentage increase in $\mathrm{s} C r \geq 50 \%$ from baseline which is known or presumed to have occurred within the last 7 days

- $\quad$ Stage 1 Increase in $\mathrm{sCr} \geq 0.3 \mathrm{mg} / \mathrm{dl}$ or an increase in $\mathrm{sCr} \geq 1$.5-fold to 2-fold from baseline

- $\quad$ Stage 2 Increase in $\mathrm{sCr}>2$-fold to 3 -fold from baseline

- $\quad$ Stage 3 Increase of $\mathrm{sCr}>3$-fold from baseline or $\mathrm{sCr} \geq 4.0 \mathrm{mg} / \mathrm{dl}$ with an acute increase $\geq 0.3 \mathrm{mg} / \mathrm{dl}$ or initiation of renal replacement therapy

\section{Hepatorenal Syndrome:}

Hepatorenal syndrome (HRS) is defined as the occurrence of renal failure in a patient with advanced liver disease, with portal hypertension and ascites, in the absence of an identifiable cause of renal failure. ${ }^{92}$ HRS is thus diagnosed by ruling other possible causes of renal failure..$^{93}$

Two studies carried out in tertiary care hospitals in Sindh, Pakistan, revealed a $15 \%$ incidence of hepatorenal syndrome in patients with cirrhosis. ${ }^{92,94}$ A similar study carried out in Egypt showed 11.3\% incidence. ${ }^{95}$ It is the most common cause of renal impairment in patients with cirrhosis with ascites $(47.4 \%)$ followed by other causes like primary renal disease, analgesic nephropathy and hypovolemia. ${ }^{94}$ The annual incidence of HRS, as reported in international literature is $7.9 \% .{ }^{93}$

Pathophysiology of hepatorenal syndrome:

Proposed mechanisms of HRS are splanchnic vasodilation which is accompanied by renal vasoconstriction. ${ }^{93,96-98}$ A decreased effective arterial blood pressure also contributes towards decreased renal perfusion. ${ }^{99,100}$ There is growing evidence to suggest that systemic inflammation as a result of bacterial infection is another precipitant of Hepatorenal Syndrome-Acute Kidney Injury (HRS-AKI). ${ }^{101,102}$ The Lipopolysaccharides released by Gram negative bacteria contribute to increased portal pressure and also promote further decompensation of liver disease. ${ }^{103,104}$

\section{Diagnosis of hepatorenal syndrome:}

There are two types of HRS. Hepatorenal syndrome type of acute kidney injury (HRS-AKI) formerly Type 1 HRS is a rapidly progressive renal failure in patients with advanced liver failure and is associated with poor prognosis. Hepatorenal syndrome type of chronic kidney disease (HRS type 2) is a slowly progressive renal failure in patients with cirrhosis and refractory ascites. ${ }^{93,96}$ Those with HRS have a poor prognosis with average median survival of three months. ${ }^{105,106}$ HRS-AKI, if left untreated, can lead to death within a month. ${ }^{106}$

The diagnostic criteria for diagnosis of HRS-AKI have recently been revised by the International ascites club in 2015. The previous definition of an absolute reading of serum creatinine $\geq 1.5 \mathrm{mg} /$ dl for diagnosis of HRS was discarded based on knowledge that patients with cirrhosis have a decreased muscle mass and also have an impaired urea cycle. Moreover, milder derangements in renal function were being missed as a result of this cut-off serum creatinine level. The criteria for urine output was also removed since patients with cirrhosis tend to retain sodium and water as a result of renin-angiotensin-activation-system and tend to be oliguric despite having normal renal function. ${ }^{107}$

The new definitions for AKI in cirrhosis are as follows ${ }^{108}$

There is a retrospective study that diagnosed HRS-AKI on the basis of the current criteria and was able to pick HRS-AKI at stage 1 in $40 \%$ of inhospital patients with cirrhosis and ascites. Those patients who had stage 1 AKI despite a serum creatinine less than $1.5 \mathrm{mg} / \mathrm{dl}$ still had 3.5 -fold 30 day mortality than those without $\mathrm{AKI}^{86}$. This further illustrates the importance of picking up even slight rise in serum creatinine level to improve mortality.

\section{PROGNOSIS:}

In a study carried out at a tertiary care hospital in Islamabad, mortality was found to be higher in patients with advanced liver disease with renal failure as compared to those without renal failure (31\% vs $4.5 \%)$. Acute kidney injury was the most common presentation and the most common etiologies of renal dysfucntion were infection and hypovolemia. Reversibility was higher with hypovolemia but greater number of deaths were seen in patients with HRS and sepsis. ${ }^{109}$

HRS type of AKI (HRS-AKI formerly type 1 HRS) The HRS-AKI is defined as International club of ascites (ICA) criteria AKI-ICA stage 2 or more while other causes of renal failure have been excluded. Thus other causes of AKI such as hypovolemia, shock, urinary tract obstruction, use of nephrotoxic medication and parenchymal diseases of kidney have been ruled out. ${ }^{101,107-109}$

The box below gives the revised diagnostic criteria for HRS-AKI 


\section{HRS-AKI}

- Diagnosis of cirrhosis and ascites

- Diagnosis of AKI according to AKI-ICA

- No response after 2 consecutive days of diuretic withdrawal and plasma expansion with albumin $1 \mathrm{~g}$ per $\mathrm{kg}$ body weight

- Absence of shock

- No current or recent use of nephrotoxic drugs (NSAIDs, aminoglycosides, non-ionic contrast etc)

- No macroscopic signs of structural kidney injury defined as*

- Absence of proteinuria ( $>500 \mathrm{mg} /$ day)

- Absence of microhematuria (>50 RBCs per high power field)

- Normal finding on renal ultrasonography

*Patients who fulfill these criteria may still have structural damage such as tubular damage. Urine biomarkers will become an important tool in differentiating between HRS and acute tubular necrosis.

HRS-AKI fails to respond to volume expansion with IV albumin or withdrawal of diuretics ${ }^{83}$. Events such as spontaneous bacterial peritonitis or bleeding from varices cause fluctuation in systemic circulation leading to HRS-AKI. ${ }^{110}$ HRS develops in approximately $30 \%$ of patients who develop spontaneous bacterial peritonitis ${ }^{89}$. HRSAKI can also occur spontaneously but it has also been seen with non-selective beta blockers that also trigger variation in systemic circulation. ${ }^{105}$

There are a few biomarkers that can be utilized for diagnosis of HRS-AKI and make it less of a diagnosis of exclusion. Urinary neutrophil gelatinase-associated lipocalin (NGAL) levels and urinary Interleukin-18 (IL-18) levels have shown a significant difference between each category of AKI. ${ }^{111-113}$ Urinary NGAL and IL-18 level is high in ATN; intermediate levels are seen in HRS and low levels in prerenal azotemia. Levels in prerenal azotemia are the same as normal individuals as well as those with stable Chronic Kidney Disease (CKD). Urinary NGAL and urine kidney injury molecule 1 (KIM-1) have been found to be useful to predict HRS in patients with cirrhosis. ${ }^{114,115}$ These biomarkers can thus serve as useful tools for diagnosis of and prediction of HRS in cirrhotic patients but their role in clinical practice is yet to be defined. Since there is glomerular tubular reflux, kidneys are not histologically normal in HRS as was previously thought. ${ }^{116}$ These urinary biomarkers will help prevent the need for renal biopsy in cirrhotic patients.

\section{HRS type of CKD (HRS type 2)}

HRS type 2 is a slowly progressive form of renal failure where there is slowly progressive deterioration of renal function in patients who have decompensated cirrhosis and refractory ascites. Patients have oliguria and salt and water retention over the course of several months with a slow but steady decline in renal function. The rest of the criteria remain the same as for HRS-AKI. ${ }^{92,93}$ Incidence of HRS type 2 varies and is reported to be between 16 and $61 \% .{ }^{92,106,117}$ Patients with HRS type 2 may ultimately develop HRS-AKI either spontaneously or a precipitating event may be involved. ${ }^{96,117}$

Patients with cirrhosis and refractory ascites may have other causes of kidney injury and HRS type 2 is a diagnosis of exclusion. Other etiologies of CKD may complicate HRS type 2 . It is therefore difficult to diagnose. The prognosis remains poor, albeit slightly better than HRS-AKI. ${ }^{110,115,118}$

\section{Recommendations}

- It is important to diagnose AKI in cirrhosis and to identify the possible etiology (I-A)

- There are two types of HRS. HRS-AKI and HRS type 2. (I-A)

- Before a diagnosis of HRS-AKI is reached, other etiologies that must be excluded are hypovolemia, shock, use of nephrotoxic medicines and agents and underlying renal parenchymal disease. (I-A)

- HRS-AKI is diagnosed by noticing even a slight rise in serum creatinine. Careful monitoring of renal function in patients with cirrhosis and ascites is crucial especially if they are hospitalized. (I-A)

- An effort must be made to identify the precipitating cause of HRS-AKI. To name a few, systemic bacterial infections, spontaneous bacterial peritonitis in particular, variceal bleed and use of non-selective beta blockers are common. (II-A)

- An early diagnosis of HRS-AKI is known to decrease mortality (I-II)

- Hallmark of HRS type 2 is a slow but constant decline in renal function and carries a poor prognosis. (I-A)

- Urinary biomarkers may be used to predict HRS-AKI and can be of help in differentiating HRS from other causes of AKI. (II-B) 


\section{MANAGEMENT OF HRS-AKI and HRS TYPE 2 General Measures:}

Once diagnosed, HRS-AKI should be treated promptly to prevent further deterioration of renal function. It is important to assess for other complications of cirrhosis and to monitor vital signs, urine output, serum electrolytes, renal and liver function tests. Such patients should ideally be managed in an intensive treatment unit and an effort should be made to measure the central venous pressure.

\section{Recommendations:}

- Once HRS-AKI has been established, patients are best managed in the ICU setting with careful monitoring of vital signs and urine output (I-A)

- Diuretics must be stopped and intravenous fluid should be monitored to avoid fluid overload and dilutional hyponatremia. (I-A)

- Once HRS has been diagnosed, a trial of furosemide may be given to maintain urine output in patients who show signs of fluid overload. Spironolactone, however, is best avoided to prevent life threatening hyperkalemia (I-A)

- Since beta blockers have been identified as potential triggers in a recent study, it is better to stop them in patients who might have been taking them earlier as prophylaxis against variceal bleed. (II-B)

- All patients with HRS-AKI should undergo screening for sepsis. Thus blood, urine and ascitic fluid cultures must be sent at first presentation. Antibiotics should be continued even if no signs of bacterial infection are found. (I-A)

- Large volume paracentesis is best avoided in an acute setting but it can be safely carried out to make patients with tense ascites more comfortable. (I-A)

Specific Therapies:

Vasoconstrictor agents and albumin:

Vasoconstrictor agents such as terlipressin, midodrine/octreotide and norepinephrine have been evaluated in combination with albumin for treatment of HRS-AKI. These agents bring about vasoconstriction in the splanchnic vasculature and increase the mean arterial pressure. Albumin is of benefit in patients with sepsis owing to its scavenging, anti-oxidant as well as endothelial stabilizing effect apart from its additional benefit of volume expansion. ${ }^{117}$

Terlipressin is initiated at a dose of $1 \mathrm{mg} 4$ to 6 hourly. Dose can go up to $2 \mathrm{mg}$ every $4-6$ hours if a reduction of more than $25 \%$ is not seen in serum creatinine on day 3 . Albumin is started at $1 \mathrm{~g}$ per $\mathrm{kg}$ body weight going upto $100 \mathrm{~g}$ on day 1 and then continued at $40 \mathrm{~g} /$ day. ${ }^{117,119} \mathrm{~A}$ dose of $12.5 \mathrm{~g} /$ day in combination with 0.5 to $1.0 \mathrm{mg}$ Terlipressin 12 hourly has also been found to be effective in a study published from Sind, Pakistan. ${ }^{120}$ A lower dose will be of help in bringing the cost of treatment down. A combination of albumin and terlipressin was shown to be of benefit in $58.3 \%$ patients with HRSAKI in a setting in Lahore, Pakistan. ${ }^{121}$ Lower serum creatinine at the time of diagnosis of HRS-AKI, absence of hyperkalemia and absence of portal vein thrombosis were seen to predict a better response to therapy. ${ }^{121}$ Terlipressin and albumin have been shown to improve short term survival only. ${ }^{119,120,122}$ Terlipressin is contraindicated in patients with ischemic heart disease. Patients must be monitored for ischemic events of extremities and splanchnic vasculature while on terlipressin.

A combination of albumin with octreotide at a dose of 200 microgram subcutaneously three times a day and oral at a titrated dose of upto $12.5 \mathrm{mg}$ three times a day has been of benefit in a few studies from the US and Europe. ${ }^{48,123}$ This combination was found to be superior to dopamine combined with albumin. ${ }^{124}$

Noradrenaline at a dose of $0.5-3 \mathrm{mg} / \mathrm{h}$ is infused continuously dose is gradually increased to achieve a raise in arterial blood pressure and improvement in renal parameters in HRS-AKI. ${ }^{125,126}$ In a metaanalysis that extracted data from four studies only, no difference in reversal of HRS, 30-day mortality or recurrence of HRS was seen between terlipressin and norepinephrine. ${ }^{127-130}$ Whereas terlipressin has been associated with cardiovascular and ischemic complications, norepinephrine was shown to have lower incidence of such adverse events. However, the ease of administration of terlipressin as a bolus dose in a peripheral vein in a ward as compared to a continuous infusion of norepinephrine in ICU setting gives a clear advantage to terlipressin despite its higher cost. ${ }^{128,131}$

These therapies can also be of short term benefit in patients with HRS-CKD but HRS tends to recur once vasoconstrictor therapy is withdrawn. ${ }^{106,110,132}$ A response is illustrated by a fall in serum creatinine, and an increase in urine output, arterial pressure and serum sodium levels. A complete response is defined by a fall in serum creatinine to a level within $0.3 \mathrm{mg} / \mathrm{dL}$ of baseline according to the International Club of Ascites (ICA) ${ }^{96,122}$ If there is no response after 72 hours of treatment, the dose 
of vasoactive agent should be increased. In those who fail to show an improvement in renal function despite 14 days of treatment, pharmacologic therapy should be discontinued. ${ }^{93,96,106,122}$ Longer treatment durations can be used in patients eligible for liver transplantation who show a response to therapy since it improves outcome after liver transplantation. ${ }^{61,119,133}$

\section{Prevention of HRS-AKI:}

Very few studies are available on prevention of HRS. Pentoxifylline showed some promise at a dose of $400 \mathrm{mg}$ three times a day in alcoholic hepatitis. ${ }^{134-136}$ Treatment of SBP aggressively also prevents development of HRS. ${ }^{137}$ Norfloxacin at a dose of $400 \mathrm{mg}$ per day reduced the incidence of HRS in child class $C$ cirrhosis. ${ }^{82}$

For prevention of HRS-AKI and HRS-CKD, albumin should be administered at a dose of $8 \mathrm{~g}$ for every litre removed when large volume paracentesis $(>5 \mathrm{~L})$ is carried out. $35,45,117$

Tranjugular intrahepatic portosystemic shunt: TIPS has been of benefit in only a handful of patients with HRS-AKI. A strong statement cannot therefore be made on it being used as an option in HRS-AKI.

It, however, has been of benefit in patients with HRS-CKD in view of improvement in renal function as well as in control of ascites. ${ }^{5-57,60}$ Patients with type 2 HRS must however be carefully evaluated for cardiac function and MELD before being considered for TIPS. TIPS should not be placed in presence of concomitant infection, progressive renal failure or cardiopulmonary disease.

\section{Renal replacement therapy:}

Randomized-controlled trials have not shown a survival benefit of renal replacement therapy (RRT such as hemodialysis) or extracorporeal liver support (ELS) for HRS-AKI and HRS-CKD. Continuous venovenous hemodialysis use may, however, be of some benefit in patients who are hemodynamically unstable. ${ }^{138}$ RRT and ELS such as MARS or Prometheus may be of benefit in patients with HRS-AKI but should be restricted to patients who are candidates for liver transplantation. ${ }^{139,140}$ Combined liver and kidney transplantation should be offered to patients on RRT for more than 12 weeks.

\section{Liver transplantation:}

Owing to the poor prognosis of HRS-AKI and HRS-CKD, these patients must be referred for liver transplantation as soon as possible. ${ }^{61,133}$ Primary graft nonfunction and 30-day mortality rates were higher and 1-, 2-, and 5-year graft and patient survival rates were lower in patients with moderate or severe renal failure. ${ }^{141-144}$ It must, however, be emphasized that this poorer outcome in comparison to patients without HRS is due to the fact that renal failure is a poor predictor of outcome of liver transplantation. With HRS contributing towards a higher MELD, patients with HRS should have an early referral for a liver transplantation. ${ }^{145,146}$

\section{Recommendations:}

\section{Management of HRS-AKI:}

- Pharmacologic therapy of terlipressin combined with albumin should be administered in patients with HRS-AKI (I-A)

- Dose of terlipressin can be administered in an incremental manner upto a maximum of $2 \mathrm{mg} / 4$ $h$ if there is less than $25 \%$ reduction of serum creatinine on day 3 (I-A)

- For those patients who do not respond, treatment should be discontinued within 14 days (I-A)

- Patients on terlipressin must be carefully watched for cardiac dysrrhythmias and for signs of ischemia of extremities and splanchnic vasculature. (I-A)

- Alternatives to terlipressin and albumin are combination of albumin with octreotide and midodrine. Unfortunately, midodrine is not available in Pakistan (II-B)

- A combination of norepinephrine and albumin is also an alternative but very little international and local data is available to support these therapies (II-B)

- There is insufficient data to prove that TIPS can be used in the setting of HRS-AKI not responding to pharmacologic therapy( II-B)

- Renal replacement therapy may be useful only as a bridge to liver transplantation. (II-B)

- HRS-AKI patients must be considered for liver transplantation (I-A)

\section{Management of HRS type 2}

- Terlipressin and albumin is of temporary benefit only in patients with HRS type 2 since HRS tends to recur once therapy is withdrawn (I-A)

- Patients with HRS-CKD should be evaluated for TIPS which might improve renal function and control ascites.(I-A)

- Patients must undergo cardiac evaluation, renal and liver function for MELD before undergoing TIPS (I-A)

- Liver transplantation improves survival in patients with HRS-CKD (I-A)

- Patients with HRS type 2 who require renal support for $>12$ weeks must be considered for 
combined kidney and liver transplantation. (IA) Prevention of HRS

- Pentoxifylline has proven to be of some patients with HRS in the setting of alcoholic hepatitis (IIA)

- Early diagnosis and management of SBP with antibiotics and albumin is known to prevent HRS (I-A)

- Large volume paracentesis is best done under cover of albumin (I-A)

\section{Suggestions for future research}

- To study the incidence of HRS-AKI and HRSCKD in light of the new International Club Ascites definitions

- To study the efficacy of lower dose of albumin in combination with terlipressin for management of HRS-AKI

- To study the response of combination of albumin and norepinephrine in the setting of HRS-AKI

- To ascertain the utility of urinary biomarkers as predictors of HRS-AKI and its diagnosis

- To study efficacy of TIPS as treatment for HRSAKI not responding to pharmacologic therapy

- To study efficacy and adverse event profile for TIPS for management of HRS type 2

\section{REFERENCES}

1. Benmassaoud A, Freeman SC, Roccarina D, Plaz Torres MC, Sutton AJ Cooper NJ, et al. Treatment for Ascites in Adults with Decompensated Liver Cirrhosis: A Network Meta-Analysis. Cochrane Database Syst Rev 2020;1(CD013123 DOI: 10.1002/14651858.CD013123.pub2.

2. Guedes RR, Kieling CO, Dos Santos JL, da Rocha C, Schwengber F, Adami MR, et al. Severity of Ascites Is Associated with Increased Mortality in Patients with Cirrhosis Secondary to Biliary Atresia. Dig Dis Sci 2020 DOI: 10.1007/s10620-019-06029-Z.

3. Macdonald S, Jepsen P, Alrubaiy L, Watson H, Vilstrup H, Jalan R Quality of Life Measures Predict Mortality in Patients with Cirrhosi and Severe Ascites. Aliment Pharmacol Ther 2019;49(3):321-330 DOI: 10.1111/apt.15084

4. Adebayo D, Neong SF, Wong F. Refractory Ascites in Liver Cirrhosis Am J Gastroenterol 2019;114(1):40-47 DOI: 10.1038/s41395-018-0185-6.

5. Mahmood K, Haider I, Adil SO, Ubaid M, Talib A. Non-Invasive Assessment of Large Esophageal Varices with Liver Cirrhosis ; a Study Conducted in Pakistan. J Med Invest 2019;66(3.4):248-251 DOI: 10.2152/jmi.66.248.

6. Parkash O, Mohyuddin GR, Ayub A, Nazir I, Maan AA, Hamid S. Electrophysiological Changes in Patients with Liver Cirrhosis in a Tertiary Care Hospital in Karachi, Pakistan. J Ayub Med Coll Abbottabad 2016;28(4):676-679.

7. Butt AS. Epidemiology of Viral Hepatitis and Liver Diseases in Pakistan. Euroasian J Hepatogastroenterol 2015;5(1):43-48 DOI: 10.5005/jpjournals-10018-1129.

8. Butt AS, Sharif F. Viral Hepatitis in Pakistan: Past, Present, and Future. Euroasian J Hepatogastroenterol 2016;6(1):70-81 DOI: 10.5005/jpjournals-10018-1172.

9. Almani SA, Memon AS, Memon AI, Shah I, Rahpoto Q, Solangi R. Cirrhosis of Liver: Etiological Factors, Complications and Prognosis. J Liaquat Uni Med Health Sci 2008;7(2):61-66.

10. Neong SF, Adebayo D, Wong F. An Update on the Pathogenesis and Clinical Management of Cirrhosis with Refractory Ascites. Expert Rev Gastroenterol Hepatol 2019;13(4):293-305 DOI: 10.1080/17474124.2018.1555469.

11. Namba M, Hiramatsu A, Aikata H, Kodama K, Uchikawa S, Ohya K, et al. Management of Refractory Ascites Attenuates Muscle Mass Reduction and Improves Survival in Patients with Decompensated Cirrhosis. J Gastroenterol 2020;55(2):217-226 DOI: 10.1007/s00535-019-01623-4.
12. Shimizu S, Ohira M, Nakano R, Imaoka $Y$, Sato $K$, Tahara H, et al. Management of Refractory Ascites for Liver Transplant Candidates: A Novel Cell-Free and Concentrated Ascites Reinfusion Therapy. Transplant Proc 2019;51(8):2740-2744 DOI: 10.1016/j. transproceed.2019.02.060.

13. Møller S, Henriksen JH, Bendtsen F. Ascites: Pathogenesis and Therapeutic Principles. Scandinavian journal of gastroenterology 2009;44(8):902-911.

14. Easl Clinical Practice Guidelines on the Management of Ascites, Spontaneous Bacterial Peritonitis, and Hepatorenal Syndrome in Cirrhosis. J Hepatol 2010;53(3):397-417 DOI: 10.1016/j. jhep.2010.05.004.

15. Sarwar S, Alam A, Izhar M, Khan AA, Butt AK, Shafqat F, et al. Bedside Diagnosis of Spontaneous Bacterial Peritonitis Using Reagent Strips. J Coll Physicians Surg Pak 2005;15(7):418-421 DOI: 07.2005/JCPSP.418421.

16. Duah A, Nkrumah KN. Spontaneous Bacterial Peritonitis among Adul Patients with Ascites Attending Korle-Bu Teaching Hospital. Ghana Med J 2019;53(1):37-43 DOI: 10.4314/gmi.v53i1.6.

17. Pericleous M, Sarnowski A, Moore A, Fijten R, Zaman M. The Clinica Management of Abdominal Ascites, Spontaneous Bacterial Peritonitis and Hepatorenal Syndrome: A Review of Current Guidelines and Recommendations. Eur J Gastroenterol Hepatol 2016;28(3):e10-18 DOI: 10.1097/MEG.0000000000000548.

18. Moore KP, Wong F, Gines P, Bernardi M, Ochs A, Salerno F, et al. The Management of Ascites in Cirrhosis: Report on the Consensus Conference of the International Ascites Club. Hepatology 2003;38(1):258 266 DOI: 10.1053 /jhep.2003.50315

19. Mohii el SM, El Mansy IM, Salah M, Khedr MA. Diagnostic Usefulness of the Random Urine Na/K Ratio in Predicting Therapeutic Response for Diuretics in Cirrhotic Patients with Ascites. J Egypt Soc Parasitol 2013;43(3):767-776 DOI: 10.12816/0006433.

20. Hou W, Sanyal AJ. Ascites: Diagnosis and Management. Med Clin North Am 2009;93(4):801-817, vii DOI: 10.1016/j.mcna.2009.03.007.

21. Bernardi M. Optimum Use of Diuretics in Managing Ascites in Patients with Cirrhosis. Gut 2010;59(01):10-11.

22. Kumar P. Role of Diuretics in the Harmful Effects of Beta Blockers in Patients with Ascites. Dig Liver Dis 2018;50(1):101-102 DOI: 10.1016/j. dld.2017.09.004.

23. Casey S, Schierwagen R, Mak KY, Klein S, Uschner F, Jansen C, et al. Activation of the Alternate Renin-Angiotensin System Correlates with the Clinical Status in Human Cirrhosis and Corrects Post Liver Transplantation. J Clin Med 2019;8(4) DOI: 10.3390/jcm8040419.

24. Yao H, Zhang C. Angiotensin Ii Receptor Blockers for the Treatment of Portal Hypertension in Patients with Liver Cirrhosis: A Systematic Review and Meta-Analysis of Randomized Controlled Trials. Ir J Med Sci 2018;187(4):925-934 DOI: 10.1007/s11845-018-1765-6.

25. Carrion AF, Radhakrishnan R, Martin P. Diagnosis and Management of Renal Dysfunction in Patients with Cirrhosis. Expert Rev Gastroenterol Hepatol 2020;14(1):1-7 DOI: 10.1080/17474124.2020.1708190.

26. Umemura T, Joshita S, Shibata S, Sugiura A, Yamazaki T, Fujimori N, et al. Renal Impairment Is Associated with Increased Risk of Mortality in Patients with Cirrhosis: A Retrospective Cohort Study. Medicine (Baltimore) 2019;98(6):e14475 DOI: 10.1097/MD.0000000000014475.

27. Yoo JJ, Kim SG, Kim YS, Lee B, Lee MH, Jeong SW, et al. Estimation of Renal Function in Patients with Liver Cirrhosis: Impact of Muscle Mass and Sex. J Hepatol 2019;70(5):847-854 DOI: 10.1016/j.jhep.2018.12.030.

28. Mayr U, Fahrenkrog-Petersen L, Batres-Baires G, Herner A, Rasch $\mathrm{S}$, Schmid RM, et al. Large-Volume Paracentesis Effects Plasma Disappearance Rate of Indo-Cyanine Green in Critically Ill Patients with Decompensated Liver Cirrhosis and Intraabdominal Hypertension. Ann Intensive Care 2018;8(1):78 DOI: 10.1186/s13613-018-0422-6.

29. Simonetti RG, Perricone G, Nikolova D, Bjelakovic G, Gluud C. Plasma Expanders for People with Cirrhosis and Large Ascites Treated with Abdominal Paracentesis. Cochrane Database Syst Rev 2019;6(CD004039 DOI: 10.1002/14651858.CD004039.pub2.

30. Tan HK, James PD, Wong F. Albumin May Prevent the Morbidity of Paracentesis-Induced Circulatory Dysfunction in Cirrhosis and Refractory Ascites: A Pilot Study. Dig Dis Sci 2016;61(10):3084-3092 DOI: 10.1007/s10620-016-4140-3.

31. Fyson J, Chapman L, Tatton M, Raos Z. Abdominal Paracentesis: Use of a Standardised Procedure Checklist and Equipment Kit Improves Procedural Quality and Reduces Complications. Intern Med J 2018;48(5):572-579 DOI: 10.1111/imj.13741.

32. Shriver A, Rudnick S, Intagliata N, Wang A, Caldwell SH, Northup P. A Randomized Controlled Trial of Procedural Techniques for Large Volume Paracentesis. Ann Hepatol 2017;16(2):279-284 DOI: 10.5604/16652681.1231587.

33. Lin $\mathrm{CH}$, Chen SC, Ko PC. Preprocedure Coagulation Tests Are Unnecessary before Abdominal Paracentesis in Emergency Departments. Hepatology 2005;41(2):402-403 DOI: 10.1002/hep.20552. 
34. Kwok CS, Krupa L, Mahtani A, Kaye D, Rushbrook SM, Phillips MG, et al. Albumin Reduces Paracentesis-Induced Circulatory Dysfunction and Reduces Death and Renal Impairment among Patients with Cirrhosis and Infection: A Systematic Review and Meta-Analysis. Biomed Res Int 2013;2013(295153 DOI: 10.1155/2013/295153.

35. Anderson SS, McCreary JB, Alvarez KS, Brown LS, Agrawal D. Standardizing the Use of Albumin in Large Volume Paracentesis. J Pharm Pract 2018:897190018816252 DOI: 10.1177/0897190018816252.

36. Alessandria C, Elia C, Mezzabotta L, Risso A, Andrealli A, Spandre M, et al. Prevention of Paracentesis-Induced Circulatory Dysfunction in Cirrhosis: Standard Vs Half Albumin Doses. A Prospective, Randomized, Unblinded Pilot Study. Dig Liver Dis 2011;43(11):881-886 DOI: $10.1016 / \mathrm{j}$. dld.2011.06.001.

37. Gines A, Fernandez-Esparrach G, Monescillo A, Vila C, Domenech E, Abecasis R, et al. Randomized Trial Comparing Albumin, Dextran 70, and Polygeline in Cirrhotic Patients with Ascites Treated by Paracentesis. Gastroenterology 1996;111(4):1002-1010 DOI: 10.1016/ s0016-5085(96)70068-9.

38. Terg R, Miguez CD, Castro L, Araldi H, Dominguez S, Rubio M. Pharmacokinetics of Dextran-70 in Patients with Cirrhosis and Ascites Undergoing Therapeutic Paracentesis. J Hepatol 1996;25(3):329-333 DOI: 10.1016/s0168-8278(96)80119-x.

39. Sola-Vera J, Minana J, Ricart E, Planella M, Gonzalez B, Torras X, et al. Randomized Trial Comparing Albumin and Saline in the Prevention of Paracentesis-Induced Circulatory Dysfunction in Cirrhotic Patients with Ascites. Hepatology 2003;37(5):1147-1153 DOI: 10.1053/jhep.2003.50169.

40. Mayr U, Karsten E, Lahmer T, Rasch S, Thies P, Henschel B, et al Impact of Large Volume Paracentesis on Respiratory Parameters Including Transpulmonary Pressure and on Transpulmonary Thermodilution Derived Hemodynamics: A Prospective Study. PLoS One 2018;13(3):e0193654 DOI: 10.1371/journal.pone.0193654.

41. Goel A, Biewald M, Huprikar S, Schiano T, Im GY. A Real-World Evaluation of Repeat Paracentesis-Guided Management of Spontaneous Bacterial Peritonitis. J Clin Gastroenterol 2017;51(3):278-284 DOI: 10.1097/MCG.0000000000000704

42. Sideris A, Patel P, Charles HW, Park J, Feldman D, Deipolyi AR. Imaging and Clinical Predictors of Spontaneous Bacterial Peritonitis Diagnosed by Ultrasound-Guided Paracentesis. Proc (Bayl Univ Med Cent) 2017;30(3):262-264 DOI: 10.1080/08998280.2017.11929610.

43. Martin DK, Walayat S, Jinma R, Ahmed Z, Ragunathan K, Dhillon S. Large-Volume Paracentesis with Indwelling Peritoneal Catheter and Albumin Infusion: A Community Hospital Study. J Community Hosp Intern Med Perspect 2016;6(5):32421 DOI: 10.3402/jchimp.v6.32421.

44. Nadir A, Van Thiel DH. Frequency of Peritoneal Infections among Patients Undergoing Continuous Paracentesis with an Indwelling Catheter. J Ayub Med Coll Abbottabad 2010;22(1):37-41.

45. Arora V, Vijayaraghavan R, Maiwall R, Sahney A, Thomas SS, Ali $\mathrm{R}$, et al. Paracentesis-Induced Circulatory Dysfunction with ModestVolume Paracentesis Is Partly Ameliorated by Albumin Infusion in Aclf Hepatology 2019 DOI: 10.1002/hep.31071.

46. Widjaja FF, Khairan P, Kamelia T, Hasan I. Colloids Versus Albumin in Large Volume Paracentesis to Prevent Circulatory Dysfunction: Evidence-Based Case Report. Acta Med Indones 2016;48(2):148-155.

47. Kasztelan-Szczerbinska B, Cichoz-Lach H. Refractory Ascites-the Contemporary View on Pathogenesis and Therapy. PeerJ 2019;7(e7855 DOI: $10.7717 /$ peerj.7855.

48. Yosry A, Soliman ZA, Eletreby R, Hamza I, Ismail A, Elkady MA. Oral Midodrine Is Comparable to Albumin Infusion in Cirrhotic Patients with Refractory Ascites Undergoing Large-Volume Paracentesis: Results of a Pilot Study. Eur J Gastroenterol Hepatol 2019;31(3):345-351 DOI: 10.1097/MEG.0000000000001277.

49. Hiruy A, Nelson J, Zori A, Morelli G, Cabrera R, Kamel A. Standardized Approach of Albumin, Midodrine and Octreotide on Hepatorenal Syndrome Treatment Response Rate. Eur J Gastroenterol Hepatol 2020 DOI: 10.1097/MEG.0000000000001700.

50. Singh V, Singh A, Agarwal R. Midodrine and Albumin in Decompensated Cirrhosis: Down but Not Out. J Hepatol 2019;70(4):811 DOI: 10.1016/j. jhep.2018.11.008.

51. Sola E, Sole C, Simon-Talero M, Martin-Llahi M, Castellote J, Garcia-Martinez R, et al. Midodrine and Albumin for Prevention of Complications in Patients with Cirrhosis Awaiting Liver Transplantation. A Randomized Placebo-Controlled Trial. J Hepatol 2018;69(6):1250-1259 DOI: 10.1016/j.jhep.2018.08.006

52. Aday AW, Rich NE, Mufti AR, Tujios SR. Con ("the Window Is Closed"): In Patients with Cirrhosis with Ascites, the Clinical Risks of Nonselective Beta-Blocker Outweigh the Benefits and Should Not Be Prescribed. Clin Liver Dis (Hoboken) 2018;11(5):123-127 DOI: 10.1002/cld.699.

53. Wong RJ, Robinson A, Ginzberg D, Gomes C, Liu B, Bhuket T. Assessing the Safety of Beta-Blocker Therapy in Cirrhosis Patients with Ascites: A Meta-Analysis. Liver Int 2019;39(6):1080-1088 DOI: 10.1111/liv.14040.
54. Bucsics T, Hoffman S, Grunberger J, Schoder M, Matzek W, Stadlmann A, et al. Eptfe-Tips Vs Repetitive Lvp Plus Albumin for the Treatment of Refractory Ascites in Patients with Cirrhosis. Liver Int 2018;38(6):10361044 DOI: $10.1111 /$ liv.13615.

55. Ronald J, Rao R, Choi SS, Kappus M, Martin JG, Sag AA, et al. No Increased Mortality after Tips Compared with Serial Large Volume Paracenteses in Patients with Higher Model for End-Stage Liver Disease Score and Refractory Ascites. Cardiovasc Intervent Radiol 2019;42(5):720728 DOI: $10.1007 /$ s00270-018-02155-9.

56. Young S, Bermudez J, Zhang L, Rostambeigi N, Golzarian J. Transjugular Intrahepatic Portosystemic Shunt (Tips) Placement: A Comparison of Outcomes between Patients with Hepatic Hydrothorax and Patients with Refractory Ascites. Diagn Interv Imaging 2019;100(5):303-308 DOI: 10.1016/j.diii.2018.10.006

57. Hamid RS, Tanveer ul h, Azeemuddin M, Sajjad Z, Chishti I, Salam B. Transjugular Intrahepatic Portosystemic Shunt (Tips); Review of Initial Experience at Aga Khan University Hospital. J Pak Med Assoc 2011;61(4):336-339.

58. Zhou C, Hou C, Cheng D, Tang W, Lv W. Predictive Accuracy Comparison of Meld and Child-Turcotte-Pugh Scores for Survival in Patients Underwent Tips Placement: A Systematic Meta-Analytic Review. Int J Clin Exp Med 2015;8(8):13464-13472.

59. Casadaban LC, Parvinian A, Zivin SP, Lakhoo J, Minocha J, Knuttinen MG, et al. Meld Score for Prediction of Survival after Emergent Tips for Acute Variceal Hemorrhage: Derivation and Validation in a 101-Patient Cohort. Ann Hepatol 2015;14(3):380-388.

60. Choe WH. Do Cirrhotic Patients with a High Meld Score Benefit from Tips? Clin Mol Hepatol 2014;20(1):15-17 DOI: 10.3350/ cmh.2014.20.1.15.

61. Al Sibae MR, Cappell MS. Accuracy of Meld Scores in Predicting Mortality in Decompensated Cirrhosis from Variceal Bleeding, Hepatorenal Syndrome, Alcoholic Hepatitis, or Acute Liver Failure as Well as Mortality after Non-Transplant Surgery or Tips. Dig Dis Sci 2011;56(4):977-987 DOI: 10.1007/s10620-010-1390-3

62. Bellos I, Kontzoglou K, Psyrri A, Pergialiotis V. Tolvaptan Response Improves Overall Survival in Patients with Refractory Ascites: A MetaAnalysis. Dig Dis 2019:1-9 DOI: 10.1159/000503559.

63. Arase Y, Kagawa T, Tsuruya K, Sato H, Teramura E, Anzai K, et al Impaired Renal Function May Not Negate the Efficacy of Tolvaptan in the Treatment of Cirrhotic Patients with Refractory Ascites. Clin Drug Investig 2019;39(1):45-54 DOI: 10.1007/s40261-018-0714-5.

64. Bellos I, Kontzoglou K, Perrea DN. Predictors of Tolvaptan ShortTerm Response in Patients with Refractory Ascites: A Meta-Analysis. J Gastroenterol Hepatol 2020;35(2):182-191 DOI: 10.1111/jgh.14784.

65. Sagawa E, Okubo H, Ando H, Sorin Y, Kanazawa R, Nakadera E, et al Plasma Concentration and Efficacy of Tolvaptan in Cirrhotic Patients with Refractory Ascites. J Pharmacol Sci 2019;139(4):373-376 DOI: 10.1016/j.jphs.2019.01.015.

66. Vinod P, Krishnappa V, Chauvin AM, Khare A, Raina R. Cardiorenal Syndrome: Role of Arginine Vasopressin and Vaptans in Heart Failure. Cardiol Res 2017;8(3):87-95 DOI: 10.14740/cr553w.

67. Bhandari S, Peri A, Cranston I, McCool R, Shaw A, Glanville J, et al. A Systematic Review of Known Interventions for the Treatment of Chronic Nonhypovolaemic Hypotonic Hyponatraemia and a Meta-Analysis of the Vaptans. Clin Endocrinol (Oxf) 2017;86(6):761-771 DOI: 10.1111/ cen.13315.

68. Karkhanis S, Jones R, Willis A, McCarthy E, Zia Z, Mehrzad H, et al. Radiological Insertion of Automated Low Flow Ascitic Pump (Alfapump ((R))) System for Management of Medically Refractory Ascites. BJR Case Rep 2017;3(4):20170025 DOI: 10.1259/bjrcr.20170025.

69. Lepida A, Marot A, Trepo E, Degre D, Moreno C, Deltenre P. Systematic Review with Meta-Analysis: Automated Low-Flow Ascites Pump Therapy for Refractory Ascites. Aliment Pharmacol Ther 2019;50(9):978987 DOI: $10.1111 /$ apt.15502.

70. Solbach P, Honer Zu Siederdissen C, Wellhoner F, Richter N, Heidrich B, Lenzen H, et al. Automated Low-Flow Ascites Pump in a Real-World Setting: Complications and Outcomes. Eur J Gastroenterol Hepatol 2018;30(9):1082-1089 DOI: 10.1097/MEG.0000000000001149.

71. Stirnimann G, Banz V, Storni F, De Gottardi A. Automated LowFlow Ascites Pump for the Treatment of Cirrhotic Patients with Refractory Ascites. Therap Adv Gastroenterol 2017;10(2):283-292 DOI: $10.1177 / 1756283$ X16684688.

72. Stirnimann G, Berg T, Spahr L, Zeuzem S, McPherson S, Lammert F et al. Treatment of Refractory Ascites with an Automated Low-Flow Ascites Pump in Patients with Cirrhosis. Aliment Pharmacol Ther 2017;46(10):981-991 DOI: 10.1111/apt.14331.

73. Wong F, Bendel E, Sniderman K, Frederick T, Haskal ZJ, Sanyal A, et al. Improvement in Quality of Life and Decrease in Large Volume Paracentesis Requirements with the Automated Low Flow Ascites Pump. Liver Transpl 2020 DOI: 10.1002/lt.25724. 
74. Zaman A, Kareem R, Mahmood R, Hameed K, Khan EM. Frequency of Microbial Spectrum of Spontaneous Bacterial Peritonitis in Established Cirrhosis Liver. J Ayub Med Coll Abbottabad 2011;23(4):15-17.

75. Bibi S, Ahmed W, Arif A, Khan F, Alam SE. Clinical, Laboratory and Bacterial Profile of Spontaneous Bacterial Peritonitis in Chronic Liver Disease Patients. J Coll Physicians Surg Pak 2015;25(2):95-99 DOI: 02.2015/JCPSP.9599.

76. Jamil S, Ahmed S, Memon A, Masood S, Ali Shah SH, Hamid SS, et al. Factors Predicting the Recurrence of Spontaneous Bacterial Peritonitis in Patients with Cirrhosis. J Coll Physicians Surg Pak 2011;21(7):407-410 DOI: 07.2011/JCPSP.407410.

77. Sajjad M, Khan ZA, Khan MS. Ascitic Fluid Culture in Cirrhotic Patients with Spontaneous Bacterial Peritonitis. J Coll Physicians Surg Pak 2016;26(8):658-661 DOI: 2399.

78. Sarwar S, Tarique S, Waris U, Khan AA. Cephalosporin Resistance in Community Acquired Spontaneous Bacterial Peritonitis. Pak J Med Sci 2019;35(1):4-9 DOI: 10.12669/pjms.35.1.17.

79. Gossman W, Foris LA, Mandiga P, Haseeb M. Spontaneous Bacterial Peritonitis. Statpearls. Treasure Island (FL) 2020.

80. Gayatri AA, Suryadharma IG, Purwadi N, Wibawa ID. The Relationship between a Model of End Stage Liver Disease Score (Meld Score) and the Occurrence of Spontaneous Bacterial Peritonitis in Liver Cirrhotic Patients. Acta Med Indones 2007;39(2):75-78.

81. Terra C, Guevara M, Torre A, Gilabert R, Fernandez J, Martin-Llahi M, et al. Renal Failure in Patients with Cirrhosis and Sepsis Unrelated to Spontaneous Bacterial Peritonitis: Value of Meld Score. Gastroenterology 2005;129(6):1944-1953 DOI: 10.1053/j.gastro.2005.09.024.

82. Marciano S, Dirchwolf M, Diaz JM, Bermudez C, Gutierrez-Acevedo MN, Barcan LA, et al. Spontaneous Bacterial Peritonitis Recurrence in Patients with Cirrhosis Receiving Secondary Prophylaxis with Norfloxacin. Eur J Gastroenterol Hepatol 2019;31(4):540-546 DOI: 10.1097/MEG.0000000000001331.

83. Abdel-Razik A, Abdelsalam M, Gad DF, Abdelwahab A, Tawfik M, Elzehery R, et al. Recurrence of Spontaneous Bacterial Peritonitis in Cirrhosis: Novel Predictors. Eur J Gastroenterol Hepatol 2019 DOI: 10.1097/MEG.0000000000001578.

84. Mo S, Bendtsen F, Wiese SS, Kimer N. Low Ascitic Fluid Total Protein Levels Is Not Associated to the Development of Spontaneous Bacterial Peritonitis in a Cohort of 274 Patients with Cirrhosis. Scand J Gastroenterol 2018;53(2):200-205 DOI: 10.1080/00365521.2017.1411973.

85. Wu H, Chen L, Sun Y, Meng C, Hou W. The Role of Serum Procalcitonin and C-Reactive Protein Levels in Predicting Spontaneous Bacterial Peritonitis in Patients with Advanced Liver Cirrhosis. Pak J Med Sci 2016;32(6):1484-1488 DOI: 10.12669/pjms.326.10995.

86. Llach J, Rimola A, Navasa M, Gines P, Salmeron JM, Gines A, et al. Incidence and Predictive Factors of First Episode of Spontaneous Bacterial Peritonitis in Cirrhosis with Ascites: Relevance of Ascitic Fluid Protein Concentration. Hepatology 1992;16(3):724-727 DOI: 10.1002/ hep. 1840160318 .

87. Bercoff E, Manchon ND, Durrbach A, Leconte N, Bourreille J. LowProtein-Concentration Ascitic Fluid and Risk of Spontaneous Bacterial Peritonitis. Gastroenterology 1987;93(4):915 DOI: 10.1016/00165085(87)90472-0.

88. Runyon BA. Low-Protein-Concentration Ascitic Fluid Is Predisposed to Spontaneous Bacterial Peritonitis. Gastroenterology 1986;91(6):1343-1346 DOI: 10.1016/0016-5085(86)90185-x

89. Rajput MR, Zuberi BF, Shaikh WM, Solangi GA, Shaikh SM, Shaikh GM. Frequency, Microbial Spectrum, Clinical and Biochemical Features of Spontaneous Bacterial Peritonitis and Its Variants. J Coll Physicians Surg Pakistan 1999;9(8):347-350.

90. Khatwani NR, Chhutto MA, Abro HA, Shaikh MA. Diagnostic Validity of Leukocyte Esterase Dipstick Test for Diagnosis of Spontaneous Bacterial Peritonitis in Cirrhotic Patients. Journal of Ayub Medical College Abbottabad 2011;23(1):51-54.

91. Glaess SS, Attridge RL, Brady RL, Attridge RT. Evaluation of Prophylactic Antibiotic Regimens on Recurrence and Mortality in Spontaneous Bacterial Peritonitis. Ann Hepatol 2019;18(6):841-848 DOI: 10.1016/j. aohep.2019.06.013.

92. Seetlani NK, Memon AR, Iftikhar F, Ali A, Fazel PA. Hepatorenal Syndrome in Patients with Cirrhosis of Liver According to 2007 International Ascites Club Criteria. J Ayub Med Coll Abbottabad 2016;28(3):578-581.

93. Ranasinghe IR, Sharma B, Bashir K. Hepatorenal Syndrome. Statpearls. Treasure Island (FL) 2020.

94. Kumar R, Ahmed R, Rathi SK, Sethar GH. Frequency of Hepatorenal Syndrome among Cirrhotics. J Coll Physicians Surg Pakistan 2005;15(10):590-593.

95. Morsy KH, Mekky MA, Abdel Malek MO, Abbas WA. Incidence, Causes, and Outcomes of Renal Failure among Cirrhotic Patients. Turk J Gastroenterol 2015;26(6):517-521.
96. Velez JCQ, Therapondos G, Juncos LA. Reappraising the Spectrum of Aki and Hepatorenal Syndrome in Patients with Cirrhosis. Nat Rev Nephrol 2020;16(3):137-155 DOI: 10.1038/s41581-019-0218-4.

97. Knotek M, Rogachev B, Schrier RW. Update on Peripheral Arterial Vasodilation, Ascites and Hepatorenal Syndrome in Cirrhosis. Can J Gastroenterol 2000;14 Suppl D(112D-121D DOI $10.1155 / 2000 / 340128$.

98. Schrier RW, Niederberger M, Weigert A, Gines P. Peripheral Arterial Vasodilatation: Determinant of Functional Spectrum of Cirrhosis. Semin Liver Dis 1994;14(1):14-22 DOI: 10.1055/s-2007-1007294.

99. Alvarado E, Garcia-Guix M, Mirabet S, Villanueva C. The Relationship of Hyperdynamic Circulation and Cardiodynamic States in Cirrhosis. J Hepatol 2018;69(3):746-747 DOI: 10.1016/j.jhep.2018.04.026.

100. Moller S, Bendtsen F. The Pathophysiology of Arterial Vasodilatation and Hyperdynamic Circulation in Cirrhosis. Liver Int 2018;38(4):570-580 DOI: $10.1111 /$ liv.13589.

101. Francoz C, Durand F. Type-1 Hepatorenal Syndrome in Patients with Cirrhosis and Infection Vs. Sepsis-Induced Acute Kidney Injury: What Matters? J Hepatol 2014;60(5):907-909 DOI: 10.1016/j.jhep.2014.02.001.

102. Salerno F, Monti V. Hepatorenal Syndrome Type 1 and Bacterial Infection: A Catastrophic Association in Patients with Cirrhosis. Hepatology 2014;59(4):1239-1241 DOI: 10.1002/hep.27015.

103. Bernardi M, Moreau R, Angeli P, Schnabl B, Arroyo V. Mechanisms of Decompensation and Organ Failure in Cirrhosis: From Periphera Arterial Vasodilation to Systemic Inflammation Hypothesis. J Hepatol 2015;63(5):1272-1284 DOI: 10.1016/j.jhep.2015.07.004

104. Wong F. Clinical Consequences of Infection in Cirrhosis: Organ Failures and Acute-on-Chronic Liver Failure. Clin Liver Dis (Hoboken) 2019;14(3):92-97 DOI: 10.1002/cld.813.

105. Wong F, Boyer TD, Sanyal AJ, Pappas SC, Escalante S, Jamil K. Reduction in Acute Kidney Injury Stage Predicts Survival in Patients with Type1 Hepatorenal Syndrome. Nephrol Dial Transplant 2019 DOI: 10.1093/ ndt/gfz048.

106. Thomson MJ, Taylor A, Sharma P, Lok AS, Tapper EB. Limited Progress in Hepatorenal Syndrome (Hrs) Reversal and Survival 2002-2018: A Systematic Review and Meta-Analysis. Dig Dis Sci 2019 DOI: 10.1007/ s10620-019-05858-2.

107. Angeli P, Gines P, Wong F, Bernardi M, Boyer TD, Gerbes A, et al Diagnosis and Management of Acute Kidney Injury in Patients with Cirrhosis: Revised Consensus Recommendations of the International Club of Ascites. Gut 2015;64(4):531-537 DOI: 10.1136/ gutjnl-2014-308874.

108. Angeli P, Gines P, Wong F, Bernardi M, Boyer TD, Gerbes A, et al Diagnosis and Management of Acute Kidney Injury in Patients with Cirrhosis: Revised Consensus Recommendations of the International Club of Ascites. J Hepatol 2015;62(4):968-974 DOI: 10.1016/j. jhep.2014.12.029.

109. Khatua CR, Sahu SK, Barik RK, Pradhan S, Panigrahi S, Mishra D, et al. Validation of International Club of Ascites Subclassification of Stage 1 Acute Kidney Injury in Chronic Liver Disease. JGH Open 2019;3(4):290294 DOI: $10.1002 /$ jgh3.12152.

110. Sohn W, Kim JH, Cho JY. Effect of Acute Kidney Injury on Long-Term Outcomes of Spontaneous Bacterial Peritonitis in Cirrhotic Patients Using the International Club of Ascites-Acute Kidney Injury Criteria. J Gastroenterol Hepatol 2019 DOI: 10.1111/jgh.14871.

111. Sisman P, Gul OO, Dirican M, Bal AS, Cander S, Erturk E. Urinary Neutrophil Gelatinase-Associated Lipocalin (Ngal) as a Marker of Diabetic Nephropathy in Type 1 Diabetic Patients. Clin Lab 2020;66(1) DOI: 10.7754/Clin.Lab.2019.190326.

112. Li H, Xu Q, Wang Y, Chen K, Li J. Serum Neutrophil GelatinaseAssociated Lipocalin (Ngal) as a Biomarker for Predicting High Dose Methotrexate Associated Acute Kidney Injury in Children with Acute Lymphoblastic Leukemia. Cancer Chemother Pharmacol 2020;85(1):95103 DOI: $10.1007 /$ s00280-019-03980-6.

113. Sirota JC, Walcher A, Faubel S, Jani A, McFann K, Devarajan P, et al. Urine Il-18, Ngal, Il-8 and Serum Il-8 Are Biomarkers of Acute Kidney Injury Following Liver Transplantation. BMC Nephrol 2013;14(17 DOI: 10.1186/1471-2369-14-17.

114. Al Fayi M, Otifi H, Alshyarba M, Dera AA, Rajagopalan P. Thymoquinone and Curcumin Combination Protects Cisplatin-Induced Kidney Injury, Nephrotoxicity by Attenuating Nfkappab, Kim-1 and Ameliorating Nrf2/Ho-1 Signalling. J Drug Target 2020:1-10 DOI: 10.1080/1061186X.2020.1722136.

115. Schulz CA, Engstrom G, Nilsson J, Almgren P, Petkovic M, Christensson A, et al. Plasma Kidney Injury Molecule-1 (P-Kim-1) Levels and Deterioration of Kidney Function over 16 Years. Nephrol Dial Transplant 2020;35(2):265-273 DOI: 10.1093/ndt/gfy382.

116. Kanel GC, Peters RL. Glomerular Tubular Reflux--a Morphologic Renal Lesion Associated with the Hepatorenal Syndrome. Hepatology 1984;4(2):242-246 DOI: 10.1002/hep.1840040212. 
117. Nguyen-Tat M, Jager J, Rey JW, Nagel M, Labenz C, Worns MA, et al. Terlipressin and Albumin Combination Treatment in Patients with Hepatorenal Syndrome Type 2. United European Gastroenterol J 2019;7(4):529-537 DOI: 10.1177/2050640619825719.

118. Charilaou P, Devani K, Petrosyan R, Reddy C, Pyrsopoulos N. Inpatient Mortality Benefit with Transjugular Intrahepatic Portosystemic Shun for Hospitalized Hepatorenal Syndrome Patients. Dig Dis Sci 2020 DOI: 10.1007/s10620-020-06136-2.

119. McClure T, Chapman B, Hey P, Testro A, Gow P. Long-Term Continuous Terlipressin Infusion in Cirrhotic Patients with Hepatorenal Syndrome or Refractory Ascites Awaiting Liver Transplantation Is Associated with an Increase in Plasma Sodium. United European Gastroenterol J 2019;7(9):1271-1273 DOI: 10.1177/2050640619878996.

120. Silawat FN, Shaikh MK, Lohana RK, Devrajani BR, Shah S, Ansari A. Efficacy of Terlipressin and Albumin in the Treatment of Hepatorenal Syndrome. World Appl Sci J 2011;12(1946-1950.

121. Sarwar S, Khan AA. Hepatorenal Syndrome:Response to Terlipressin and Albumin and Its Determinants. Pak J Med Sci 2016;32(2):274-278 DOI: $10.12669 /$ pjms.322.9315.

122. Kalambokis GN, Tsiakas I, Christaki M, Koustousi C, Christou L, Baltayiannis G, et al. Systemic Hemodynamic Response to Terlipressin Predicts Development of Hepatorenal Syndrome and Survival in Advanced Cirrhosis. Eur J Gastroenterol Hepatol 2018;30(6):659-667 DOI: 10.1097/MEG.0000000000001088.

123. Nutu OA, Manrique Municio A, Marcacuzco Quinto A, Calvo Pulido J, Jimenez Romero C. Using Octreotide for Refractory Ascites after Liver Transplantation. Rev Esp Enferm Dig 2019;111(11):882-884 DOI: 10.17235/reed.2019.6316/2019.

124. Nadeem R. Midodrine Helps Early Discharge of Patients from the Icu, Though Results in Higher Rate of Natural Death. Crit Care Med 2020;48(1):e79 DOI: 10.1097/CCM.0000000000004067.

125. Gupta K, Rani P, Rohatgi A, Verma M, Handa S, Dalal K, et al. Noradrenaline for Reverting Hepatorenal Syndrome: A Prospective, Observational, Single-Center Study. Clin Exp Gastroenterol 2018;11(317324 DOI: $10.2147 /$ CEG.S153858.

126. Satsangi S. Noradrenaline for Hepatorenal Syndrome in Patients with Acute on Chronic Liver Failure: Hope Remains! Hepatology 2018;68(6):2443-2444 DOI: 10.1002/hep.30283.

127. Saif RU, Dar HA, Sofi SM, Andrabi MS, Javid G, Zargar SA. Noradrenaline Versus Terlipressin in the Management of Type 1 Hepatorenal Syndrome: A Randomized Controlled Study. Indian J Gastroenterol 2018;37(5):424 429 DOI: $10.1007 / \mathrm{s} 12664-018-0876-3$.

128. Mattos AZ, Mattos AA, Ribeiro RA. Terlipressin Versus Noradrenaline in the Treatment of Hepatorenal Syndrome: Systematic Review with Meta-Analysis and Full Economic Evaluation. Eur J Gastroentero Hepatol 2016;28(3):345-351 DOI: 10.1097/MEG.0000000000000537.

129. Mattos AZ, Mattos AA, Ribeiro RA. Terlipressin Versus Noradrenaline for Hepatorenal Syndrome. Economic Evaluation under the Perspective of the Brazilian Public Health System. Arq Gastroenterol 2016;53(2):123 126 DOI: 10.1590/S0004-28032016000200014.

130. Goyal O, Sidhu SS, Sehgal N, Puri S. Noradrenaline Is as Effective as Terlipressin in Hepatorenal Syndrome Type 1: A Prospective, Randomized Trial. J Assoc Physicians India 2016;64(9):30-35.

131. Celis P, Rada G. Noradrenaline or Terlipressin for HepatorenalSyndrome? Medwave 2015;15 Suppl 2(e6235 DOI: 10.5867/medwave.2015.6235.

132. Sole C, Sola E, Huelin P, Carol M, Moreira R, Cereijo U, et al. Characterization of Inflammatory Response in Hepatorenal Syndrome: Relationship with Kidney Outcome and Survival. Liver Int 2019;39(7):1246-1255 DOI: 10.1111/liv.14037.

133. Park GC, Hwang S, Jung DH, Song GW, Ahn CS, Kim KH, et al. Is Renal Replacement Therapy Necessary in Deceased Donor Liver Transplantation Candidates with Hepatorenal Syndrome?: A 2-Year Experience at a High-Volume Center. Ann Surg Treat Res 2020;98(2):102109 DOI: 10.4174/astr.2020.98.2.102.

134. Lee YS, Kim HJ, Kim JH, Yoo YJ, Kim TS, Kang SH, et al. Treatment of Severe Alcoholic Hepatitis with Corticosteroid, Pentoxifylline, or Dual Therapy: A Systematic Review and Meta-Analysis. J Clin Gastroenterol 2017;51(4):364-377 DOI: 10.1097/MCG.0000000000000674

135. Philips CA, Phadke N, Ganesan K, RanadeS, Augustine P. Corticosteroids, Nutrition, Pentoxifylline, or Fecal Microbiota Transplantation for Severe Alcoholic Hepatitis. Indian J Gastroenterol 2018;37(3):215-225 DOI: 10.1007/s12664-018-0859-4.

136. Taslidere E, Vardi N, Esrefoglu M, Ates B, Taskapan C, Yologlu S. The Effects of Pentoxifylline and Caffeic Acid Phenethyl Ester in the Treatment of D-Galactosamine-Induced Acute Hepatitis in Rats. Hum Exp Toxicol 2016;35(4):353-365 DOI: 10.1177/0960327115586820.

137. Ferrarese A, Pellone M, Cattelan AM, Burra P, Senzolo M. Antibiotic Therapy for Spontaneous Bacterial Peritonitis in Acute-on-Chronic Liver Failure: Handle with Care. Dig Liver Dis 2020;52(1):116-117 DOI: 10.1016/j.dld.2019.06.010.
138. Niewinski G, Raszeja-Wyszomirska J, Hrenczuk M, Rozga A, Malkowsk P, Rozga J. Intermittent High-Flux Albumin Dialysis with Continuous Venovenous Hemodialysis for Acute-on-Chronic Liver Failure and Acute Kidney Injury. Artif Organs 2020;44(1):91-99 DOI: 10.1111/ aor.13532.

139. Gonwa TA. Should Mars and Prometheus Be Used in Patients with Liver Disease? Semin Dial 2014;27(3):228-231 DOI: 10.1111/sdi.12213.

140. Faenza S, Baraldi O, Bernardi M, Bolondi L, Coli L, Cucchetti A, et al. Mars and Prometheus: Our Clinical Experience in Acute Chronic Liver Failure. Transplant Proc 2008;40(4):1169-1171 DOI: 10.1016/j. transproceed.2008.03.069.

141. Wey A, Gustafson SK, Salkowski N, Kasiske BL, Skeans M, Schaffhausen CR, et al. Association of Pretransplant and Posttransplant Program Ratings with Candidate Mortality after Listing. Am J Transplant 2019;19(2):399-406 DOI: 10.1111/ajt.15032.

142. Kwong AJ, Goel A, Mannalithara A, Kim WR. Improved Posttransplan Mortality after Share 35 for Liver Transplantation. Hepatology 2018;67(1):273-281 DOI: 10.1002/hep.29301.

143. Majernikova M, Rosenberger J, Prihodova L, Jarcuskova M, Roland R, Groothoff JW, et al. Posttransplant Anemia as a Prognostic Factor of Mortality in Kidney-Transplant Recipients. Biomed Res Int 2017:2017(6987240 DOI: 10.1155/2017/6987240.

144. Han SS, Han M, Park JY, An JN, Park S, Park SK, et al. Posttransplan Hyponatremia Predicts Graft Failure and Mortality in Kidney Transplantation Recipients: A Multicenter Cohort Study in Korea. PLoS One 2016;11(5):e0156050 DOI: 10.1371/journal.pone.0156050.

145. Perito ER, Bucuvalas J, Lai JC. Functional Status at Listing Predicts Waitlist and Posttransplant Mortality in Pediatric Liver Transplant Candidates. Am J Transplant 2019;19(5):1388-1396 DOI: 10.1111/ ajt.15203.

146. Ferrante ND, Goldberg DS. Transplantation in Foreign Nationals Lower Rates of Waitlist Mortality and Higher Rates of Lost to Followup Posttransplant. Am J Transplant 2018;18(11):2663-2669 DOI: 10.1111/ ajt.15005.

\section{Authors Contributions}

BA: Revised manuscript and gave final approval, AS: Wrote a section of manuscript

AA: Wrote a section of manuscript, BFZ: Revised and did final editing of manuscript, literature search \& updated citations and references, ZA: Wrote a section of manuscript

LK: Wrote a section of manuscript, JIF: Wrote a section of manuscript, MS: Wrote a section of manuscript, AAN: Wrote a section of manuscript, AAC: Wrote a section of manuscript, ZYH: Wrote a section of manuscript, MS: Wrote a section of manuscript.

Authors:

Bushra Ali,

Adnan Salim

Altaf Alam

Bader Faiyaz Zuberi,

Dow Medical College, Dow University of Health Sciences, Karachi, Pakistan.

Zeeshan Ali,

Jinnah Postgraduate Medical Centre, Karachi, Pakistan.

6. Zahid Azam,

NILGID, Dow University of Health Sciences, Karachi, Pakistan.

7. Lubna Kamani,

Liaquat National Hospital, Karachi, Pakistan.

8. Javed Iqbal Farooqi,

Lady Reading Hospital, Peshawar, Pakistan.

9. Muhammed Salih,

Quaid e Azam International Hospital, Islamabad, Pakistan.

10. Arif Amir Nawaz,

11. Asad Ali Chaudhry,

Gujranwala Liver Centre Gujranwala, Pakistan.

12. Zahid Yasin Hashmi,

Liver Center, Faisalabad, Pakistan.

13. Masood Siddique,

Jinnah Memorial Hospital, Rawalpindi, Pakistan.

1,10: Fatima Memorial Medical and Dental College,

Lahore, Pakistan.

2,3: Shaikh Zayed Postgraduate Medical Institute, Lahore, Pakistan. 